\title{
Optimized Microstructure and Improved Magnetic Properties of Pr-Dy-Al-Ga Diffused Sintered Nd-Fe-B Magnets
}

\author{
Pengpeng Qu ${ }^{1,2}$, Feifei Li ${ }^{1,2}$, Sajjad Ur Rehman ${ }^{1,2}$, Lei He ${ }^{1,2}$, Xiaoqiang Yu 1,2, Qingfang Huang 1,3, \\ Munan Yang ${ }^{1,2,4}$ and Jiajie $\mathrm{Li}^{1,2,4, *}$
}

1 Jiangxi Key Laboratory for Rare Earth Magnetic Materials and Devices, Institute for Rare Earth Magnetic Materials and Devices (IREMMD), Jiangxi University of Science and Technology, Ganzhou 341000, China; qppwrx@163.com (P.Q.); lifeifei1997@yeah.net (F.L.); sajjadurehman@gmail.com (S.U.R.); helyangy@163.com (L.H.); yuxiaoqiang@jxust.edu.cn (X.Y.); sduhqf@163.com (Q.H.); yangmunan@jxust.edu.cn (M.Y.)

2 College of Rare Earths, Jiangxi University of Science and Technology, Ganzhou 341000, China

3 Fujian Rare-Earth Function Material Key Laboratory, Longyan 364000, China

4 National Rare Earth Functional Materials Innovation Center, Ganzhou 341000, China

* Correspondence: lijiajie@jxust.edu.cn

Citation: Qu, P.; Li, F.; Rehman, S.U.; He, L.; Yu, X.; Huang, Q.; Yang, M.; Li, J. Optimized Microstructure and Improved Magnetic Properties of Pr-Dy-Al-Ga Diffused Sintered Nd-Fe-B Magnets. Materials 2021, 14 , 2583. https://doi.org/10.3390/ ma14102583

Academic Editor: Frank Czerwinski

Received: 15 April 2021

Accepted: 11 May 2021

Published: 16 May 2021

Publisher's Note: MDPI stays neutral with regard to jurisdictional claims in published maps and institutional affiliations.

Copyright: (c) 2021 by the authors. Licensee MDPI, Basel, Switzerland. This article is an open access article distributed under the terms and conditions of the Creative Commons Attribution (CC BY) license (https:// creativecommons.org/licenses/by/ $4.0 /)$.

\begin{abstract}
The grain boundary diffusion process (GBDP) has become an important technique in improving the coercivity and thermal stability of Dy-free sintered $\mathrm{Nd}-\mathrm{Fe}-\mathrm{B}$ magnets. The influence of $\mathrm{Dy}_{70} \mathrm{Al}_{10} \mathrm{Ga}_{20}$ and $\left(\mathrm{Pr}_{75} \mathrm{Dy}_{25}\right)_{70} \mathrm{Al}_{10} \mathrm{Ga}_{20}$ alloys by the GBDP on sintered Nd-Fe-B magnets are investigated in this paper. After diffusing $\mathrm{Dy}_{70} \mathrm{Al}_{10} \mathrm{Ga}_{20}$ and $\left(\operatorname{Pr}_{75} \mathrm{Dy}_{25}\right)_{70} \mathrm{Al}_{10} \mathrm{Ga}_{20}$ alloys, the coercivity $\left(H_{\mathrm{cj}}\right)$ of the magnets increased from $13.58 \mathrm{kOe}$ to $20.10 \mathrm{kOe}$ and $18.11 \mathrm{kOe}$, respectively. Meanwhile, the remanence of the magnets decreased slightly. The thermal stability of the diffused magnets was improved by the GBDP. The microstructure shows continuous Rare-earth-rich (RE-rich) grain boundary phases and $(\mathrm{Dy}, \mathrm{Pr} / \mathrm{Nd})_{2} \mathrm{Fe}_{14} \mathrm{~B}$ core-shell structures which contribute to improving the coercivity. Moreover, the Dy concentration on the surface of the $\left(\operatorname{Pr}_{75} \mathrm{Dy}_{25}\right)_{70} \mathrm{Al}_{10} \mathrm{Ga}_{20}$ diffused magnets decreased with the Pr substitution for the Dy element. The openness of the recoil loops for the $\left(\operatorname{Pr}_{75} \mathrm{Dy}_{25}\right)_{70} \mathrm{Al}_{10} \mathrm{Ga}_{20}$ diffused magnets is smaller than that of the original magnets and Dy ${ }_{70} \mathrm{Al}_{10} \mathrm{Ga}_{20}$ diffused magnets. The results show that the $\left(\operatorname{Pr}_{75} \mathrm{Dy}_{25}\right)_{70} \mathrm{Al}_{10} \mathrm{Ga}_{20}$ alloys can effectively optimize the microstructure and improve the magnetic properties and thermal stability of the sintered Nd-Fe-B magnets.
\end{abstract}

Keywords: Nd-Fe-B magnets; grain boundary diffusion process; magnetic properties; thermal stability; recoil loops

\section{Introduction}

Sintered Nd-Fe-B magnets possessing excellent high intrinsic coercivity and energy products are widely used in wind power, hybrid vehicles, maglev trains, and household appliances, etc. [1,2]. In this application, higher magnetism is required. Since the invention of $\mathrm{Nd}-\mathrm{Fe}-\mathrm{B}$ magnets in 1983 , the remanence $\left(J_{\mathrm{r}}\right)$ and the maximum energy product $(\mathrm{BH})_{\max }$ of the Nd-Fe-B magnets reached the theoretical values, while the $H_{\mathrm{cj}}$ is only $30 \%$ of the theoretical value [3]. However, the higher $H_{\mathrm{cj}}$ is urgently proposed in the face of increasingly harsh working environments, especially in high-temperature and high-humidity climates [4-6]. There are basically two ways to develop high coercivity. One is to improve the inherent temperature dependence of $H_{\mathrm{cj}}$, and the other is to develop higher coercivity at room temperature to resist thermal demagnetization of the magnets when exposed to high temperature. Heavy rare earth elements $\mathrm{Dy} / \mathrm{Tb}$ can be substituted for $\mathrm{Pr} / \mathrm{Nd}$ to increase the magneto-crystalline anisotropy field $\left(H_{\mathrm{A}}\right)$, causing a substantial enhancement of $H_{\mathrm{cj}}$ by a single alloying method. However, due to the antiferromagnetic coupling between Dy and $\mathrm{Fe}$, it is unfavorable to the saturation magnetization $[7,8]$. In order not to sacrifice the 
saturation magnetization, the GBDP (grain boundary diffusion process) technique was proposed by Park et al. [9]. Heavy rare earth elements can be selectively diffused into the magnet interior along the grain boundary (GB), forming a hard core-shell structure surrounding the main grains. Later, researchers successively used heavy rare earth metals/compounds/alloys containing Dy or Tb, such as Dy, $\mathrm{Dy}_{2} \mathrm{O}_{3}, \mathrm{DyF}_{3}, \mathrm{DyH}_{2}$, and $\mathrm{Dy}-\mathrm{Cu}$ or Pr-Dy-Cu [10-14] acting as diffusion sources to improve the $H_{\mathrm{cj}}$.

In the GBDP, there are large amounts of the Dy/Tb element enriched on the magnets near-surface by diffusing the $\mathrm{Dy} / \mathrm{Tb}$, which causes thicker $\mathrm{Dy} / \mathrm{Tb}$-rich shells. Some findings show that the thickness of the Tb-rich shell can be reduced by controlling the thickness of $\mathrm{TbF}_{3}$ coatings and Al-aided $\mathrm{TbH}_{2}$ powders' diffusion $[15,16]$, which can still enhance the $H_{\mathrm{cj}}$ increment. Therefore, we can design suitable diffusion resources to decrease the thickness of the Dy/Tb-rich shell on the near-surface of the magnets.

In addition, the non-rare-earth elements $\mathrm{Al} / \mathrm{Ga} / \mathrm{Cu}$ can also increase the $H_{\mathrm{cj}}$ of the sintered Nd-Fe-B magnets and reduce the irreversible loss of magnetic flux. These elements mainly enrich in the RE-rich (Rare-earth rich) liquid phase to improve the wettability and increase the coercivity of the magnets [17-19]. Therefore, we select the ternary alloy $\operatorname{Pr}_{70} \mathrm{Al}_{10} \mathrm{Ga}_{20}$ and $\mathrm{Dy}_{70} \mathrm{Al}_{10} \mathrm{Ga}_{20}$ and quaternary alloy $\left(\operatorname{Pr}_{75} \mathrm{Dy}_{25}\right)_{70} \mathrm{Al}_{10} \mathrm{Ga}_{20}$ as the diffusion sources in this work. The $\left(\operatorname{Pr}_{75} \mathrm{Dy}_{25}\right)_{70} \mathrm{Al}_{10} \mathrm{Ga}_{20}$ alloys inculcate the best properties with a large substitution of Pr for Dy after the GBDP, as shown in Supplementary Material. The magnetic properties and thermal stability of the diffused magnets are analyzed. The relationship between microstructure and recoil loops and diffusion mechanism of the magnets are also discussed.

\section{Materials and Methods}

The commercial sintered Nd-Fe-B magnet of N52 was selected and wire-cut into small magnets with a size of $\varphi 10 \times 10 \times 5 \mathrm{~mm}^{3}$, and the chemical composition was ( $\mathrm{Pr}$, $\mathrm{Nd})_{30} \mathrm{Co}_{1.0} \mathrm{Cu}_{0.15} \mathrm{Zr}_{0.12} \mathrm{Ga}_{0.3} \mathrm{~B}_{0.94} \mathrm{Fe}_{\text {bal. }}$ (wt.\%). The ingots of $\operatorname{Pr}_{70} \mathrm{Al}_{10} \mathrm{Ga}_{20}, \mathrm{Dy}_{70} \mathrm{Al}_{10} \mathrm{Ga}_{20}$, and $\left(\operatorname{Pr}_{75} \mathrm{Dy}_{25}\right)_{70} \mathrm{Al}_{10} \mathrm{Ga}_{20}$ (wt.\%) were prepared by arc melting under a high-purity argon atmosphere. Then, these ingots were melt-spun into ribbons with $10 \mathrm{~mm}$ in width and $0.17 \mathrm{~mm}$ in thickness at a speed of $8 \mathrm{~m} / \mathrm{s}$. The magnets were polished with 400 mesh, 800 mesh, 1000 mesh, 1500 mesh, and 2000 mesh sandpaper and then ultrasonically washed in alcohol and dried. The ribbons were placed on the top and bottom of the magnet and put in a sintering furnace for diffusion heat treatment. The heat treatments were carried out at $850{ }^{\circ} \mathrm{C}$ for $6 \mathrm{~h}$, and then annealed at $490^{\circ} \mathrm{C}$ for $3 \mathrm{~h}$ in a vacuum $\left(10^{-4} \mathrm{~Pa}\right)$ tubular furnace. The magnetic properties at different temperatures were measured by a boron hydride tracer (NIM-500C, National Institute of Metrology, Beijing, China). The melting points of the alloys were measured by differential scanning calorimetry (DSC250, TA Instruments, USA). Additionally, the microstructure of the magnets was observed by a field emission scanning electron microscope (FESEM, MLA650F, FLIR Systems, Inc., Wilsonville, OR, USA). The irreversible magnetic flux loss at elevated temperatures was measured by pulling Helmholtz coils. The phase constitution of the magnets was determined by the $\mathrm{X}$-ray diffraction with a $\mathrm{Cu}-\mathrm{K}_{\alpha}$ radiation (XRD, D8 Advance, Bruker, Billerica, MA, USA). The elemental distribution of Nd-Fe-B magnets was explored by using an electron probe microanalyzer (EPMA, JXA-8530F, JEOL, Tokyo, Japan). The recoil loops of the magnets were measured by the Physical Property Measurement System (PPMS-DynaCOOL1-9, Quantum Design, San Diego, CA, USA) in fields up to $5 \mathrm{~T}$ at room temperature.

\section{Results and Discussion}

Figure 1 shows the DSC results of the $\mathrm{Dy}_{70} \mathrm{Al}_{10} \mathrm{Ga}_{20},\left(\operatorname{Pr}_{75} \mathrm{Dy}_{25}\right)_{70} \mathrm{Al}_{10} \mathrm{Ga}_{20}$, and $\mathrm{Pr}_{70} \mathrm{Al}_{10} \mathrm{Ga}_{20}$ ribbons. Compared with ternary alloys, quaternary alloys have relatively lower melting points. Additionally, the lower melting point may reduce the activation energy of the diffusion and improve diffusion efficiency. Moreover, compared with the ternary alloy $\mathrm{Dy}_{70} \mathrm{Al}_{10} \mathrm{Ga}_{20}$, the quaternary alloy $\left(\mathrm{Pr}_{75} \mathrm{Dy}_{25}\right)_{70} \mathrm{Al}_{10} \mathrm{Ga}_{20}$ contains less heavy rare earth elements; thus, it reduces the costs. 


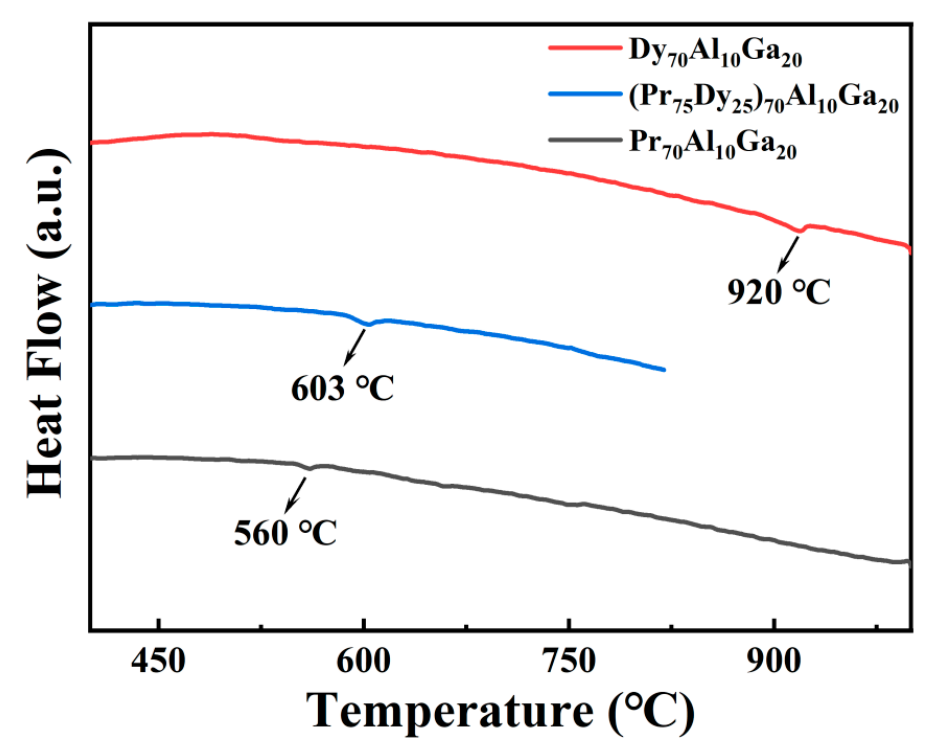

Figure 1. DSC results of $\mathrm{Dy}_{70} \mathrm{Al}_{10} \mathrm{Ga}_{20},\left(\operatorname{Pr}_{75} \mathrm{Dy}_{25}\right)_{70} \mathrm{Al}_{10} \mathrm{Ga}_{20}$, and $\mathrm{Pr}_{70} \mathrm{Al}_{10} \mathrm{Ga}_{20}$ ribbons.

Figure 2 shows demagnetization curves at the room temperature of the original magnets and $\operatorname{Pr}_{70} \mathrm{Al}_{10} \mathrm{Ga}_{20}$, Dy ${ }_{70} \mathrm{Al}_{10} \mathrm{Ga}_{20}$, and $\left(\operatorname{Pr}_{75} \mathrm{Dy}_{25}\right)_{70} \mathrm{Al}_{10} \mathrm{Ga}_{20}$ diffused magnets. It can be clearly seen that the $H_{\mathrm{cj}}$ of the diffused magnets is improved after the GBDP, while the remanence is only slightly decreased. The coercivity increased from $13.58 \mathrm{kOe}$ to $15.34 \mathrm{kOe}$, $20.10 \mathrm{kOe}$, and $18.11 \mathrm{kOe}$, respectively, after diffusing $\operatorname{Pr}_{70} \mathrm{Al}_{10} \mathrm{Ga}_{20}, \mathrm{Dy}_{70} \mathrm{Al}_{10} \mathrm{Ga}_{20}$, and $\left(\operatorname{Pr}_{75} \mathrm{Dy}_{25}\right)_{70} \mathrm{Al}_{10} \mathrm{Ga}_{20}$ alloys. At the same time, the $J_{\mathrm{r}}$ reduced from $14.3 \mathrm{kG}$ to $14.0 \mathrm{kG}$, $14.0 \mathrm{kG}$, and $14.1 \mathrm{kG}$, respectively. The increase in the $H_{\mathrm{cj}}$ is mainly because of the partial substitution of Pr and Dy for $\mathrm{Nd}$ to form the core-shell structure of (Dy, $\mathrm{Pr} / \mathrm{Nd})_{2} \mathrm{Fe}_{14} \mathrm{~B}$. The antiferromagnetic coupling of $\mathrm{Dy}$ and Fe atoms reduces the $J_{\mathrm{r}}$ of $\mathrm{Dy}_{70} \mathrm{Al}_{10} \mathrm{Ga}_{20}$ and $\left(\operatorname{Pr}_{75} \mathrm{Dy}_{25}\right)_{70} \mathrm{Al}_{10} \mathrm{Ga}_{20}$ diffused magnets. In addition, the Pr content in the $\operatorname{Pr}_{70} \mathrm{Al}_{10} \mathrm{Ga}_{20}$ diffused magnet is higher, and the nonmagnetic volume fraction increases after diffusion, which leads to the decrease in the $J_{\mathrm{r}}$. The increase in the volume fraction of the non-magnetic phases in the grain boundary is another reason for the decrease in the $J_{\mathrm{r}}$.

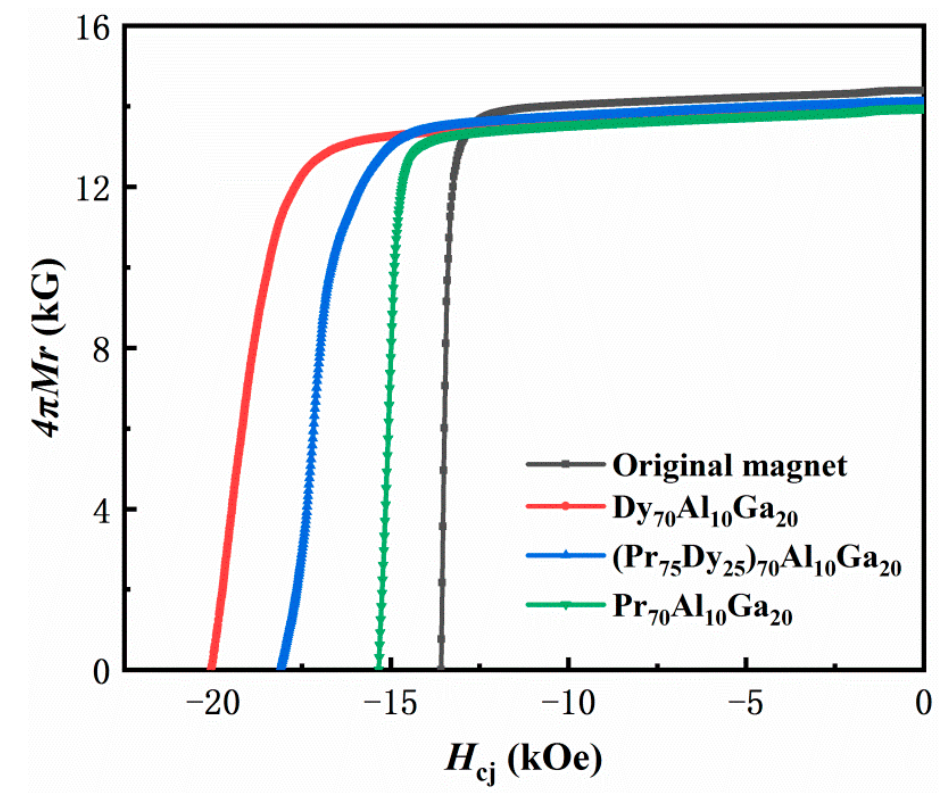

Figure 2. Demagnetization curves of the original magnet and $\operatorname{Pr}_{70} \mathrm{Al}_{10} \mathrm{Ga}_{20}, \mathrm{Dy}_{10} \mathrm{Al}_{10} \mathrm{Ga}_{20}$ and $\left(\mathrm{Pr}_{75} \mathrm{Dy}_{25}\right)_{70} \mathrm{Al}_{10} \mathrm{Ga}_{20}$ diffused magnets. 
Figure 3a shows the coercivity curves of the original magnet and the $\mathrm{Dy}_{70} \mathrm{Al}_{10} \mathrm{Ga}_{20}$ and $\left(\operatorname{Pr}_{75} \mathrm{Dy}_{25}\right)_{70} \mathrm{Al}_{10} \mathrm{Ga}_{20}$ diffused magnets at the temperature range of 293 to $453 \mathrm{~K}$. Additionally, the temperature coefficient of coercivity $(\beta)$ of the magnets can be calculated according to the formula $[20,21]$ :

$$
\beta H_{\mathrm{cj}}\left(T_{0}\right)=\left[H_{\mathrm{cj}}\left(T_{1}\right)-H_{\mathrm{cj}}\left(T_{0}\right)\right] /\left(T_{1}-T_{0}\right) \times 100 \%
$$

where $T_{1}$ is the elevated temperature, and $T_{0}$ is the room temperature. The $\beta$ increased from $-0.5341 \% / \mathrm{K}$ of the original magnets to $-0.4609 \% / \mathrm{K}$ and $-0.4939 \% / \mathrm{K}$, respectively, for the $\mathrm{Dy}_{70} \mathrm{Al}_{10} \mathrm{Ga}_{20}$ and $\left(\mathrm{Pr}_{75} \mathrm{Dy}_{25}\right)_{70} \mathrm{Al}_{10} \mathrm{Ga}_{20}$ diffused magnets. Figure $3 \mathrm{~b}$ is the irreversible flux loss curve of the original magnet and the diffused $\mathrm{Dy}_{70} \mathrm{Al}_{10} \mathrm{Ga}_{20}$ and $\left(\operatorname{Pr}_{75} \mathrm{Dy}_{25}\right)_{70} \mathrm{Al}_{10} \mathrm{Ga}_{20}$ magnets at 293-453 K. The irreversible flux loss rates of the original magnet and the $\mathrm{Dy}_{70} \mathrm{Al}_{10} \mathrm{Ga}_{20}$ and $\left(\mathrm{Pr}_{75} \mathrm{Dy}_{25}\right)_{70} \mathrm{Al}_{10} \mathrm{Ga}_{20}$ alloy diffused magnets were $75.5 \%, 48.6 \%$, and $48.7 \%$, respectively. The irreversible flux loss of the magnets was reduced by about $27 \%$ after diffusion, which suggests that the diffused magnets have less magnetic irreversible flux losses. The magnetic flux and coercivity are very sensitive to temperature. The structure loss occurs at a high temperature, which leads to demagnetization. The irreversible flux loss is not recoverable when back to room temperature. It is related to the irreversible change of the microstructure of the magnets. The GB microstructure of the diffused magnets was optimized after thermal diffusion treatment. The nucleation of the reverse magnetic domain of the magnets is suppressed, and it is difficult to trigger the magnetization reversal of the magnetic domain due to the hardening of the epitaxial layer of the matrix phase grain [22]. This results in an improvement in temperature coefficients and irreversible magnetic flux losses of the diffused magnets. These results indicate that the thermal stability of the diffused magnets was improved after the GBDP.
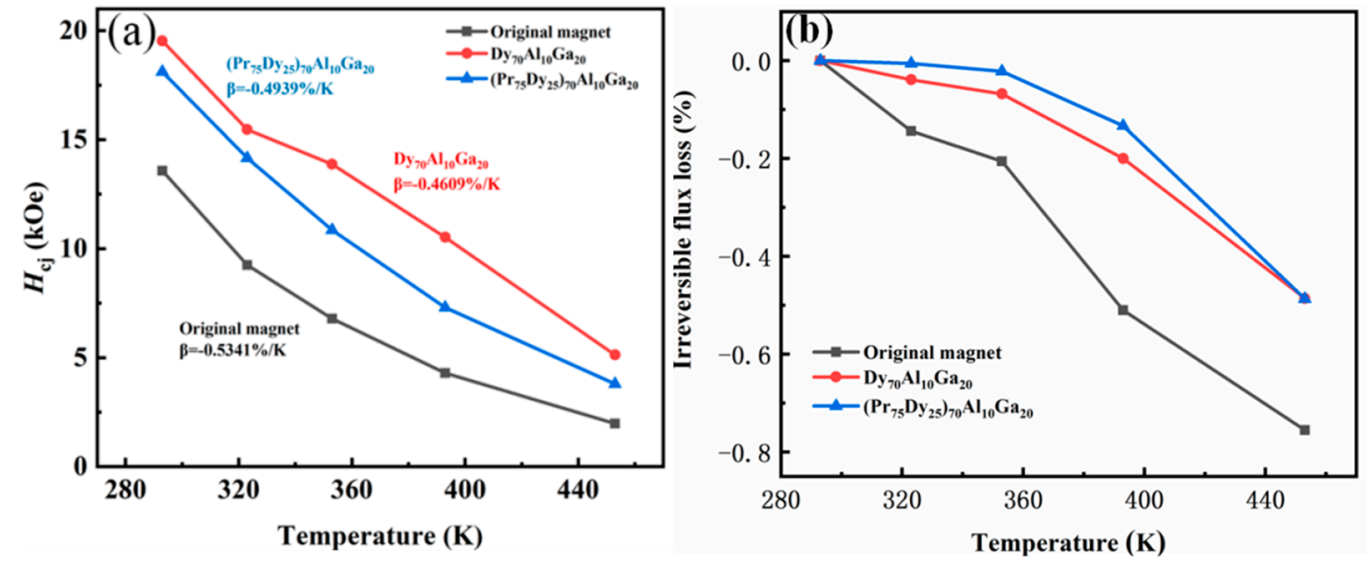

Figure 3. (a) the coercivity curves of the original magnets and the $\mathrm{Dy}_{70} \mathrm{Al}_{10} \mathrm{Ga}_{20}$ and $\left(\mathrm{Pr}_{75} \mathrm{Dy}_{25}\right)_{70} \mathrm{Al}_{10} \mathrm{Ga}_{20} \mathrm{diffusion}$ magnets in the temperature range of $293-453 \mathrm{~K}$; $(\mathbf{b})$ the irreversible flux loss curve of the original magnets and the diffused $\mathrm{Dy}_{70} \mathrm{Al}_{10} \mathrm{Ga}_{20}$ and $\left(\mathrm{Pr}_{75} \mathrm{Dy}_{25}\right)_{70} \mathrm{Al}_{10} \mathrm{Ga}_{20}$ magnets at $293-453 \mathrm{~K}$.

Figure 4 shows the XRD of the original magnets and the $\mathrm{Dy}_{70} \mathrm{Al}_{10} \mathrm{Ga}_{20}$ and $\left(\operatorname{Pr}_{75} \mathrm{Dy}_{25}\right)_{70} \mathrm{Al}_{10} \mathrm{Ga}_{20}$ diffused magnets (vertical to the c-axis plane, with the observation surface near the surface). As can be seen from the diffraction peaks marked in Figure 4, most of the diffraction peaks are the main phases, and small parts are the RE-rich phase, and no new diffraction peaks appear in the diffused magnets. The characteristic diffraction peaks were located at 29.3, 44.6, 60.8, and 78.5 of $2 \theta$, and Bragg diffraction peaks corresponding to (001) are compared with JCPDS (Joint Committee on Powder Diffraction Standards) card no. 39-0473. This indicates that the magnets are dominated by 2:14:1 phases before and after the GBDP, and the content of other impurity phases is relatively small. The partially enlarged view of the diffraction peaks of the (006) crystal plane shows that the main phase peak of the magnet shifted to a large angle direction after diffusing 
Dy ${ }_{70} \mathrm{Al}_{10} \mathrm{Ga}_{20}$, while the main phase peak moved slightly to a small angle direction after diffusing $\left(\mathrm{Pr}_{75} \mathrm{Dy}_{25}\right)_{70} \mathrm{Al}_{10} \mathrm{Ga}_{20}$. This is because the atomic radius of $\mathrm{Dy}(0.1773 \mathrm{~nm})$ is smaller than $\mathrm{Nd}(0.1821 \mathrm{~nm})$. According to the Bragg equation, when the Dy atoms diffuse into the main phase to replace $\mathrm{Nd}$ to form the $(\mathrm{Nd}, \mathrm{Dy})_{2} \mathrm{Fe}_{14} \mathrm{~B}$ shell layer, the lattice parameters decrease. For the $\left(\operatorname{Pr}_{75} \mathrm{Dy}_{25}\right)_{70} \mathrm{Al}_{10} \mathrm{Ga}_{20}$ diffused magnet, the lattice parameters of the main phase increase, which is because the diffusion amount of $\mathrm{Pr}$ is greater than that of Dy. Based on the Lanthanide contraction effect, the atomic radius of the Dy element is smaller than that of Pr and Nd. Dy instead of Pr/Nd makes the diffraction peaks move to the large angle; in contrast, $\mathrm{Pr}$ and $\mathrm{Nd}$ move the peak to a small angle. Consequently, the combined effect is that the diffraction peak shifts to a small angle. The shift of the peak also means that $\operatorname{Pr}$ and Dy have entered into the main phase, forming a stronger $H_{\mathrm{A}}$ of (Dy, $\mathrm{Pr} / \mathrm{Nd})_{2} \mathrm{Fe}_{14} \mathrm{~B}$ shells, thus exhibiting the coercivity enhancement effect.

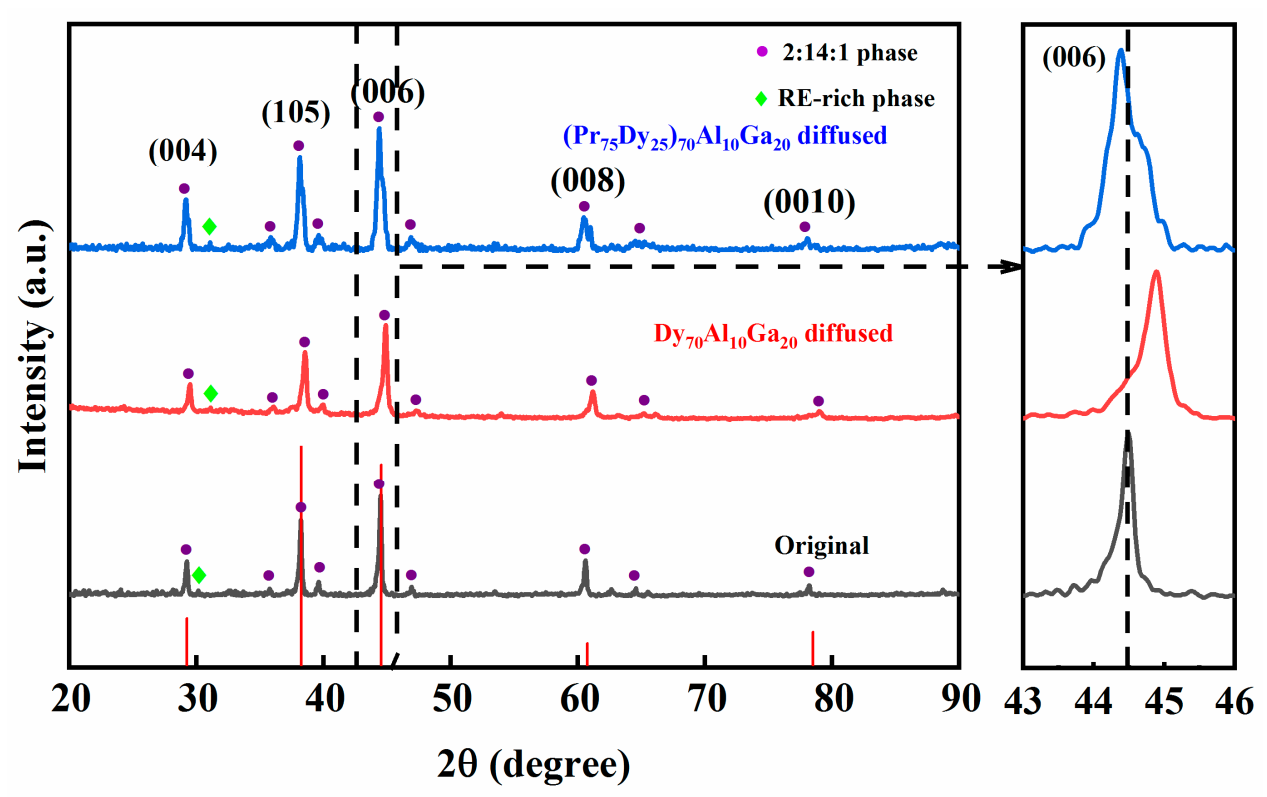

Figure 4. XRD patterns of the original magnet, and $\mathrm{Dy}_{70} \mathrm{Al}_{10} \mathrm{Ga}_{20}$ and $\left(\mathrm{Pr}_{75} \mathrm{Dy}_{25}\right)_{70} \mathrm{Al}_{10} \mathrm{Ga}_{20}$ alloy diffused magnets (the surface of observation is the near-surface).

In order to explore the reason for the $H_{\mathrm{cj}}$ enhancement, the microstructure of the magnets was observed after the GBDP. Figure 5a-c are BSE-SEM (backscattered electron) images of the original magnets, and the $\mathrm{Dy}_{70} \mathrm{Al}_{10} \mathrm{Ga}_{20}$ and $\left(\operatorname{Pr}_{75} \mathrm{Dy}_{25}\right)_{70} \mathrm{Al}_{10} \mathrm{Ga}_{20}$ alloy diffused magnets, respectively. The dark gray parts in Figure 5 correspond to the 2:14:1 matrix phase grains, and the bright white and gray white areas correspond to the RE-rich phases. The bright white and gray white in SEM are caused by the difference in composition of the RE-rich phases. Figure 5a shows that the triple junction RE-rich phases of the original magnets were distributed discretely in the magnet interior, and some adjacent matrix phase grains were in direct contact, which is unfavorable to the $H_{\mathrm{cj}}$. Comparably, the smooth and continuous thin grain boundary RE-rich phases were formed in the $\mathrm{Dy}_{70} \mathrm{Al}_{10} \mathrm{Ga}_{20}$ and $\left(\operatorname{Pr}_{75} \mathrm{Dy}_{25}\right)_{70} \mathrm{Al}_{10} \mathrm{Ga}_{20}$ diffused magnets. If all grains are surrounded by thin grain boundary phases, then the grains are magnetically isolated from each other. If the grains are in direct contact with each other, there will be a localized exchange coupling effect, and, as a result, the grains are connected together to form a larger ferromagnetic domain grain group. A small grain inversion will drive demagnetization of adjacent grains in chains, because there is no thin layer RE-rich phase boundary, which will not hinder the displacement of the domain wall [23]. Demagnetization of one grain will drive demagnetization of other grains, thus reducing coercivity; that is, the demagnetization resistance will be reduced. 

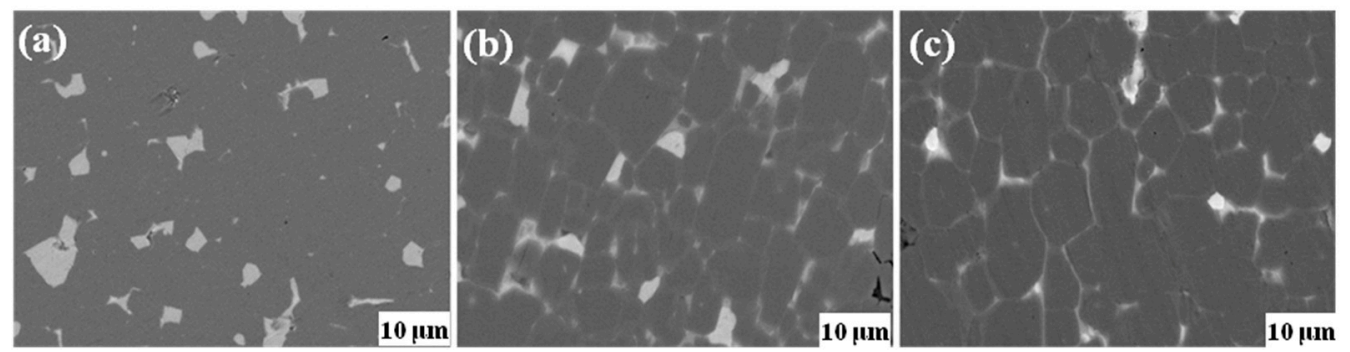

Figure 5. (a-c) are BSE-SEM images of the original magnet, and the $\mathrm{Dy}_{70} \mathrm{Al}_{10} \mathrm{Ga}_{20}$ and $\left(\mathrm{Pr}_{75} \mathrm{Dy}_{25}\right)_{70} \mathrm{Al}_{10} \mathrm{Ga}_{20}$ alloy diffused magnets (the surface of observation is the near-surface), respectively.

Figure 6 shows the EPMA images on the surface (perpendicular to c-axis) of the $\mathrm{Dy}_{70} \mathrm{Al}_{10} \mathrm{Ga}_{20}$ and $\left(\mathrm{Pr}_{75} \mathrm{Dy}_{25}\right)_{70} \mathrm{Al}_{10} \mathrm{Ga}_{20}$ diffused magnets. The distribution of $\mathrm{Dy}, \mathrm{Nd}, \mathrm{Pr}$, $\mathrm{Al}$, and $\mathrm{Ga}$ elements in the $\mathrm{Dy}_{70} \mathrm{Al}_{10} \mathrm{Ga}_{20}$ and $\left(\mathrm{Pr}_{75} \mathrm{Dy}_{25}\right)_{70} \mathrm{Al}_{10} \mathrm{Ga}_{20}$ magnets are shown in Figure 6 after the GBDP, respectively. Dy elements are mainly distributed in the main phase grain epitaxial layer to form the (Dy, $\mathrm{Pr} / \mathrm{Nd})_{2} \mathrm{Fe}_{14} \mathrm{~B}$ core-shell structure, which is beneficial to increase the coercivity. During the GBDP, Dy penetrates into the Nd-Fe-B sintered magnets through liquid grain boundaries. The Dy-rich shells are only selectively formed on the low-index lattice plane of the main phase grains. These planes, generated by the partial melting of the main phase grains, offer the low-energy configurations at the $\mathrm{Nd}_{2} \mathrm{Fe}_{14} \mathrm{~B} / \mathrm{GB}$ interfaces [24]. During the subsequent cooling process, the Dy-rich liquid phases precipitate on the edge of the main phase grains and solidify to form $(\mathrm{Nd}, \mathrm{Dy})_{2} \mathrm{Fe}_{14} \mathrm{~B}$ hard shells. As shown in Figure 6a, a large amount of Dy elements accumulated on the surface of the $\mathrm{Dy}_{70} \mathrm{Al}_{10} \mathrm{Ga}_{20}$ diffused magnets, while the enrichment on the $\left(\operatorname{Pr}_{75} \mathrm{Dy}_{25}\right)_{70} \mathrm{Al}_{10} \mathrm{Ga}_{20}$ diffused magnets is mitigated. Although the $H_{\mathrm{cj}}$ of the $\left(\operatorname{Pr}_{75} \mathrm{Dy}_{25}\right)_{70} \mathrm{Al}_{10} \mathrm{Ga}_{20}$ diffused magnet is $2 \mathrm{kOe}$ lower than that of the $\mathrm{Dy}_{70} \mathrm{Al}_{10} \mathrm{Ga}_{20}$ diffused one, the heavy rare earth content of the quaternary alloy is much lower than the ternary alloy.

The grain boundary channels, and intergranular regions of the sintered Nd-Fe-B magnets, are typically around $100-1000 \mathrm{~nm}$ in size, and the high temperature wettability causes enough capillary thrust for these elements to enter the intergranular channels during liquefaction, which in turn causes the uniform distribution of grain boundaries with the matrix grains $[25,26]$. According to the distribution of $\mathrm{Al}$ and $\mathrm{Ga}$ in Figure $6 \mathrm{~b}$, most of them remain in the grain boundaries and play a role in wetting the grain boundaries [18]. At the same time, a small amount of $\mathrm{Al}$ also exists in the matrix grains, which is possible when the surface of the Nd-Fe-B grains is partially decomposed, and Dy replaces Nd atoms. Meanwhile, Al penetrates into the selected grain facets from the grain boundaries with a high concentration at the grain edges. With a cooling effect coming in place, lighter $\mathrm{Al}$ atoms get transported inwards due to the low melting point while matrix restructuring happens, known as core-shell morphology [27]. Although the core-shells are not obvious, a higher concentration of $\operatorname{Pr}$ at the grain boundaries takes precedence of surface diffusion by the substitution of $\mathrm{Nd}$ atoms, resulting in the intergranular region becoming richer with $\mathrm{Nd}$ and hard phase grains taking composition $(\mathrm{Pr}, \mathrm{Nd})_{2} \mathrm{Fe}_{14} \mathrm{~B}$. Therefore, under the combined effect of the above elements, the hard core-shell structure and optimized microstructure can explain the reason why the diffused magnets have an increased $H_{\mathrm{cj}}$ after GBDP.

To investigate the diffusion depth of Dy in different diffused magnets, the EPMA was performed to determine the distribution of the Dy element along the diffusion direction. Figure $7(\mathrm{a} 1, \mathrm{a} 2, \mathrm{~b} 1, \mathrm{~b} 2)$ show the corresponding EPMA mappings at $0-400 \mu \mathrm{m}$ of $\mathrm{Dy}_{70} \mathrm{Al}_{10} \mathrm{Ga}_{20}$ and $\left(\operatorname{Pr}_{75} \mathrm{Dy}_{25}\right)_{70} \mathrm{Al}_{10} \mathrm{Ga}_{20}$ diffused magnets. As can be seen from Figure 7(a2,b2), a high concentration of the Dy-rich area is formed on the surface of the magnet, and the Dy-rich area is indicated by the red ellipses in Figure $7(\mathrm{a} 2, \mathrm{~b} 2)$. It can be seen from the red rectangular box that the concentration of the Dy element in the $\left(\operatorname{Pr}_{75} \mathrm{Dy}_{25}\right)_{70} \mathrm{Al}_{10} \mathrm{Ga}_{20}$ diffused magnets is higher than that of the $\mathrm{Dy}_{70} \mathrm{Al}_{10} \mathrm{Ga}_{20}$ diffused magnets. With the diffusion depth increasing, the Dy-rich area gradually decreases. At the depth of $400 \mu \mathrm{m}$, the Dy element still exists in the magnet interior. At the same time, it is observed that the concentration of Dy in 
the $\left(\operatorname{Pr}_{75} \mathrm{Dy}_{25}\right)_{70} \mathrm{Al}_{10} \mathrm{Ga}_{20}$ diffused magnets is higher than that of the $\mathrm{Dy}_{70} \mathrm{Al}_{10} \mathrm{Ga}_{20}$ diffused magnets at the same depth as the dotted lines in Figure 7(a2,b2). Therefore, the quaternary alloy $\left(\operatorname{Pr}_{75} \mathrm{Dy}_{25}\right)_{70} \mathrm{Al}_{10} \mathrm{Ga}_{20}$ can save the Dy elements and promote its diffusion depth.

\section{○ c-axis}
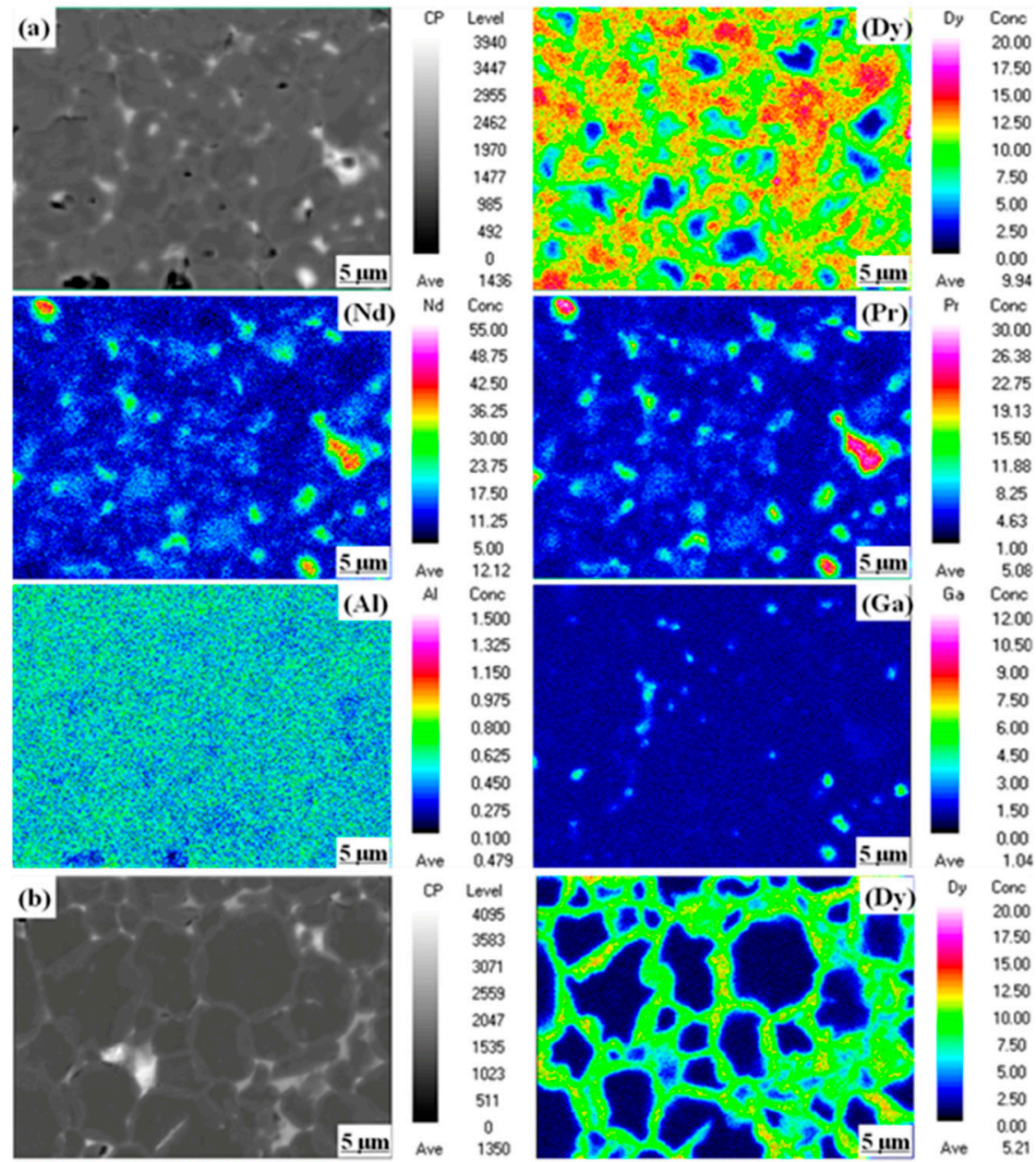

Lovel
4095
3583
3071
2559
2047
1535
1023
511
0
1350
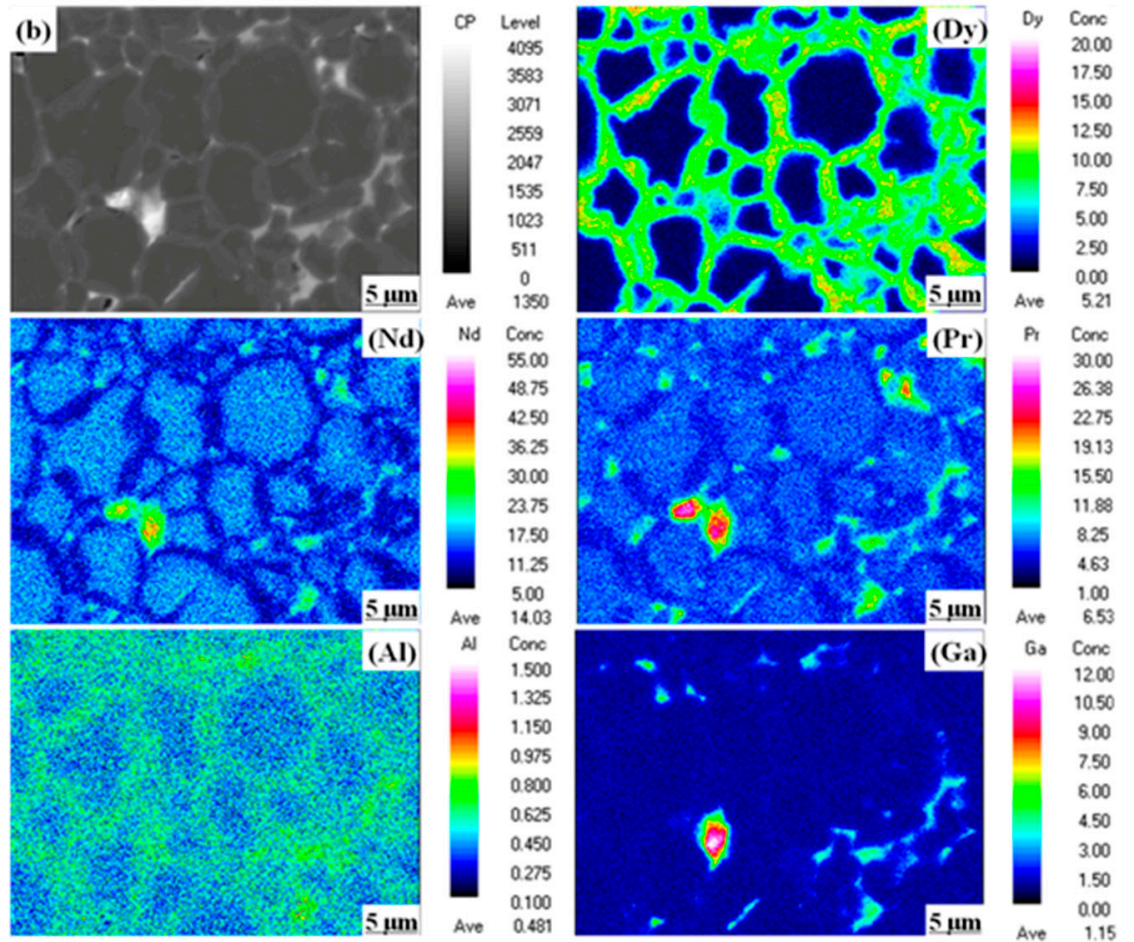

Figure 6. The EPMA mappings of the near-surface layer (perpendicular to c-axis): (a) $\mathrm{Dy}_{70} \mathrm{Al}_{10} \mathrm{Ga}_{20}$ magnet; (b) $\left(\operatorname{Pr}_{75} \mathrm{Dy}_{25}\right)_{70} \mathrm{Al}_{10} \mathrm{Ga}_{20}$ magnet. 


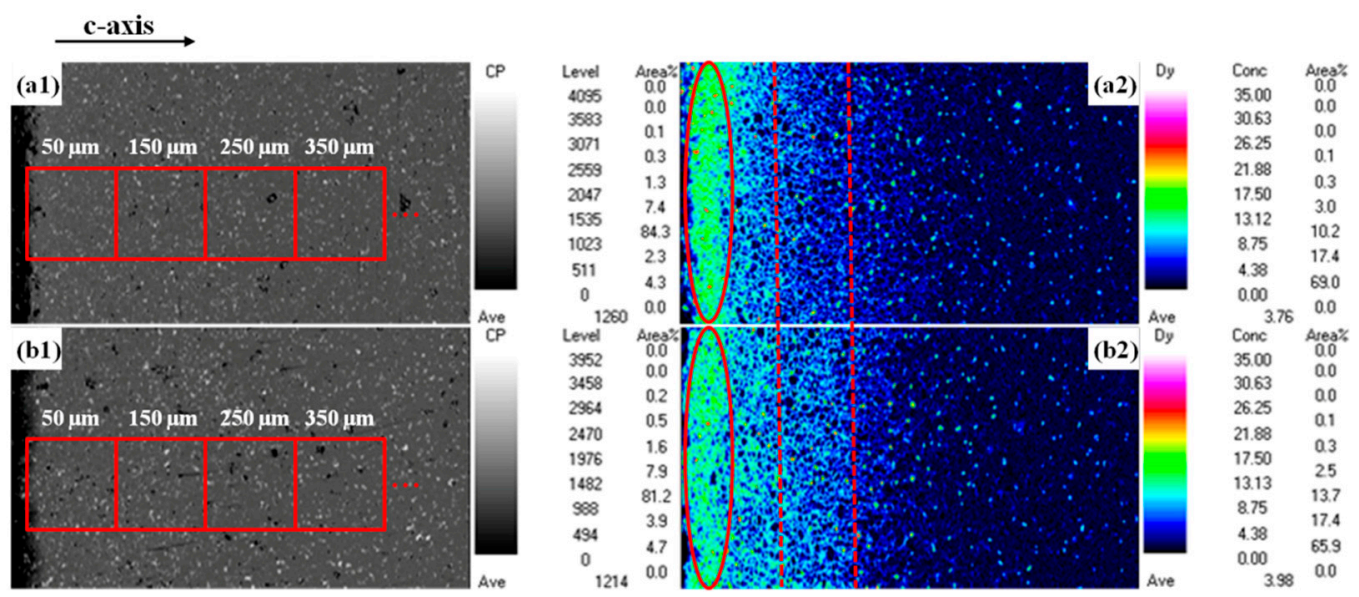

Figure 7. The SEM images and the corresponding EPMA mapping (parallel to c-axis) at $0-400 \mu \mathrm{m}$ of $(\mathbf{a} 1, \mathbf{a} 2) \mathrm{Dy}_{70} \mathrm{Al}_{10} \mathrm{Ga}_{20}$ and (b1,b2) $\left(\operatorname{Pr}_{75} \mathrm{Dy}_{25}\right)_{70} \mathrm{Al}_{10} \mathrm{Ga}_{20}$ diffused magnets, respectively.

For sintered Nd-Fe-B, the GB provides a channel for the diffusion source. The melting point of the RE-rich grain boundary phase is about $655^{\circ} \mathrm{C}$, which is much lower than the melting point of the main phase of $1185^{\circ} \mathrm{C}$ [28]. The element diffusion follows the Fick's second law, which states that in the process of unsteady diffusion, we get

$$
c_{x}=c_{0} \times \exp \left(-x^{2} / A\right)+c_{s}
$$

where $c_{x}, c_{0}$, and $c_{\mathrm{s}}$ are the volume concentrations of the diffusion material $\left(\mathrm{kg} / \mathrm{m}^{3}\right)$ at the different depths; $A$ is a fixed value (when the surface concentration and time are determined); and $x$ is the distance (m) [7]. Figure 8 shows the fitting curve of the Dy element concentration in the range of different depths in the diffused magnets. Additionally, the diffusion coefficients of the Dy element are approximately $4.988 \pm 0.673 \times 10^{-7} \mathrm{~cm}^{2} / \mathrm{s}$ and $3.139 \pm 0.101 \times 10^{-7} \mathrm{~cm}^{2} / \mathrm{s}$ in the $\left(\operatorname{Pr}_{75} \mathrm{Dy}_{25}\right)_{70} \mathrm{Al}_{10} \mathrm{Ga}_{20}$ and $\mathrm{Dy}_{70} \mathrm{Al}_{10} \mathrm{Ga}_{20}$ diffused magnets, respectively. This also shows that the diffusion efficiency of the Dy elements in the quaternary alloys $\left(\operatorname{Pr}_{75} \mathrm{Dy}_{25}\right)_{70} \mathrm{Al}_{10} \mathrm{Ga}_{20}$ is improved under the cooperation of the Pr elements. The concentration of the Dy element can be measured by EPMA along the diffusion direction from the $0 \mu \mathrm{m}$ to $450 \mu \mathrm{m}$ in a continuous $100 \times 100 \mu \mathrm{m}^{2}$ square indicated by the red boxes in Figure 7(a1,b1). As the diffusion depth increases, the concentration of Dy elements decreases, and the diffusion rate slows down.

Figure 9 gives a schematic diagram of the change in the amount of diffusion distinguished from the depth of the diffused magnets [29]. Figure 9a,b show the diffusion mechanism of ternary alloys $\mathrm{Dy}_{70} \mathrm{Al}_{10} \mathrm{Ga}_{20}$ and quaternary alloys $\left(\operatorname{Pr}_{75} \mathrm{Dy}_{25}\right)_{70} \mathrm{Al}_{10} \mathrm{Ga}_{20}$, respectively. During the heat treatment, Dy atoms enter the magnet along the grain boundaries. By replacing Nd atoms with Dy atoms, a thin layer with higher Dy concentration is formed on the edge of the main phase grains, which is called the core-shell structure. The quaternary alloys $\left(\operatorname{Pr}_{75} \mathrm{Dy}_{25}\right)_{70} \mathrm{Al}_{10} \mathrm{Ga}_{20}$ have the coordinated diffusion of the Pr element, so that the Dy element can penetrate deeper into the magnets and form a more core-shell structure. At the same time, the surface Dy concentration of the magnets can be regulated by diffusing $\left(\operatorname{Pr}_{75} \mathrm{Dy}_{25}\right)_{70} \mathrm{Al}_{10} \mathrm{Ga}_{20}$ alloys. Due to the magnetic isolation effect of the grain boundaries and the high magnetocrystalline anisotropy field of the core-shell structure, the coercivities of the diffused magnets show improvement after the GBDP treatment. 


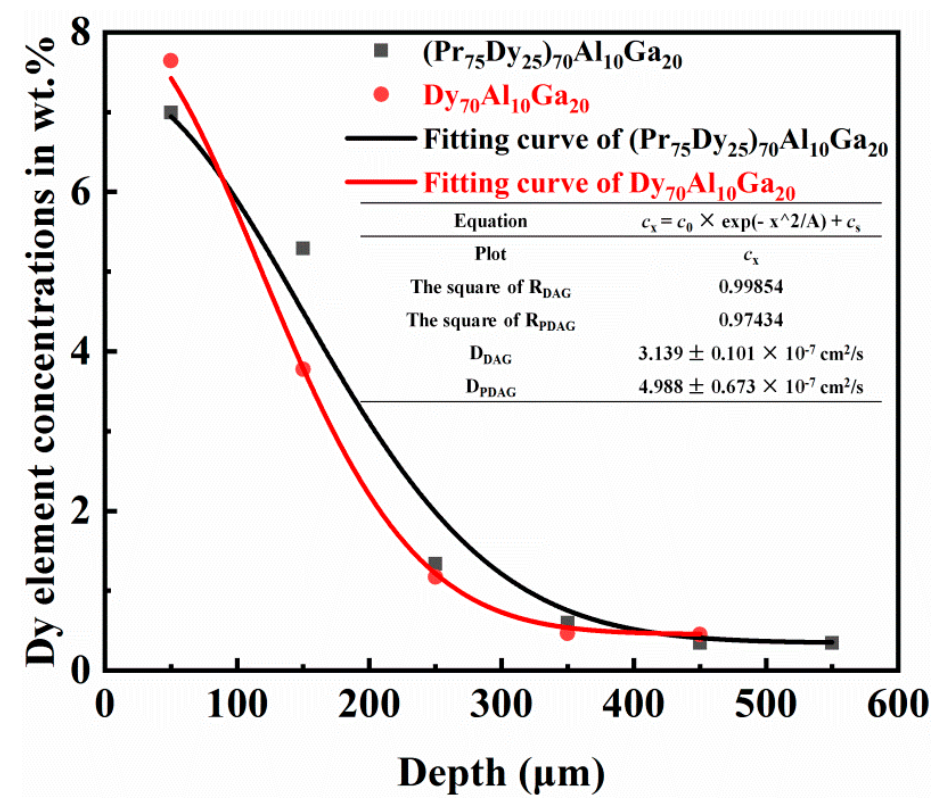

Figure 8. The fitting curves of Dy element concentration in $\left(\operatorname{Pr}_{75} \mathrm{Dy}_{25}\right)_{70} \mathrm{Al}_{10} \mathrm{Ga}_{20}$ diffused magnets at different depths.
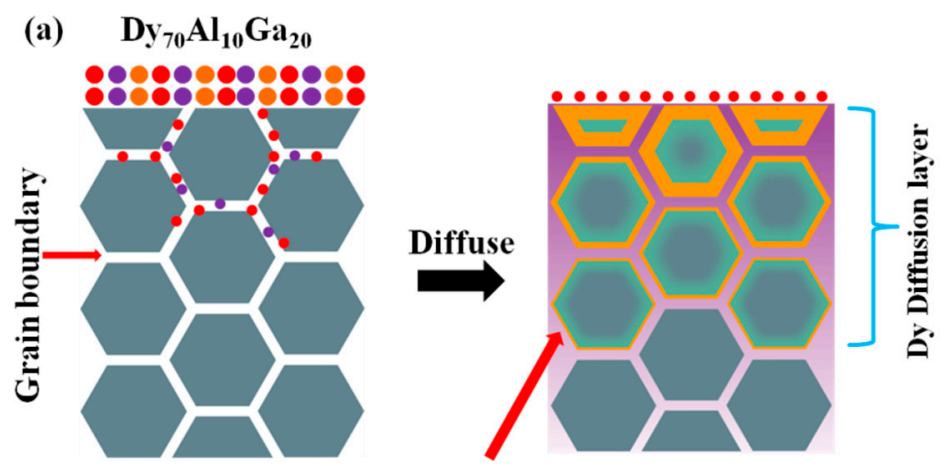

(b) $\left(\operatorname{Pr}_{75} \mathrm{Dy}_{25}\right)_{70} \mathrm{Al}_{10} \mathrm{Ga}_{20}$
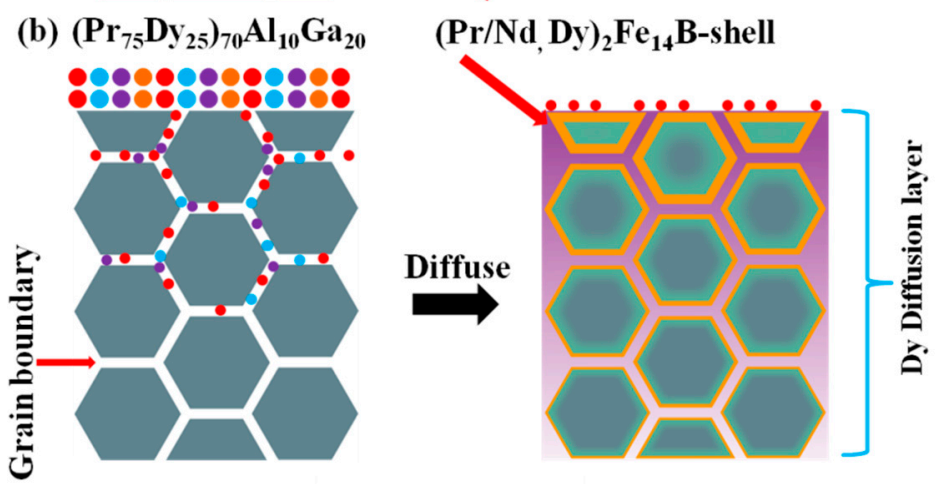

-Dy atom • Pratom • Al atom • Ga atom

Figure 9. Schematic diagram of the Nd-Fe-B magnet diffused structure. (a) the $\mathrm{Dy}_{70} \mathrm{Al}_{10} \mathrm{Ga}_{20}$ diffused magnet; (b) the $\left(\operatorname{Pr}_{75} \mathrm{Dy}_{25}\right)_{70} \mathrm{Al}_{10} \mathrm{Ga}_{20}$ diffused magnet.

The recoil loops can verify the magnitude of the demagnetization capability and the uniformity of the microstructure [17]. Figure 10 shows the recoil loops of the original magnets, and the $\mathrm{Dy}_{70} \mathrm{Al}_{10} \mathrm{Ga}_{20}$ and $\left(\mathrm{Pr}_{75} \mathrm{Dy}_{25}\right)_{70} \mathrm{Al}_{10} \mathrm{Ga}_{20}$ diffused magnets. It shows that the recoil loops' opening of the original magnet is larger, while that of the $\mathrm{Dy}_{70} \mathrm{Al}_{10} \mathrm{Ga}_{20}$ and $\left(\operatorname{Pr}_{75} \mathrm{Dy}_{25}\right)_{70} \mathrm{Al}_{10} \mathrm{Ga}_{20}$ diffused magnets are much smaller. This is because the distribution of the RE-rich phase for the original magnet is non-uniform and discontinuous, and the grain boundary of the $\mathrm{Dy}_{70} \mathrm{Al}_{10} \mathrm{Ga}_{20}$ and $\left(\mathrm{Pr}_{75} \mathrm{Dy}_{25}\right)_{70} \mathrm{Al}_{10} \mathrm{Ga}_{20}$ diffused magnets are optimized 
to be more uniform and continuous after the GBDP. However, a large amount of the Dy element enrichment on the surface of the $\mathrm{Dy}_{70} \mathrm{Al}_{10} \mathrm{Ga}_{20}$ diffused magnets leads to the larger opening of the recoil loops than that of the $\left(\operatorname{Pr}_{75} \mathrm{Dy}_{25}\right)_{70} \mathrm{Al}_{10} \mathrm{Ga}_{20}$ diffused magnets. The reduced surface Dy enrichment improves the microstructure uniformity by diffusing the $\left(\operatorname{Pr}_{75} \mathrm{Dy}_{25}\right)_{70} \mathrm{Al}_{10} \mathrm{Ga}_{20}$ alloy; thus, the recoil loops' opening of the $\left(\operatorname{Pr}_{75} \mathrm{Dy}_{25}\right)_{70} \mathrm{Al}_{10} \mathrm{Ga}_{20}$ diffused magnets is smaller than that of the original and $\mathrm{Dy}_{70} \mathrm{Al}_{10} \mathrm{Ga}_{20}$ diffused magnets. This is also confirmed by the microstructure of the magnets mentioned in Figures 5 and 6.
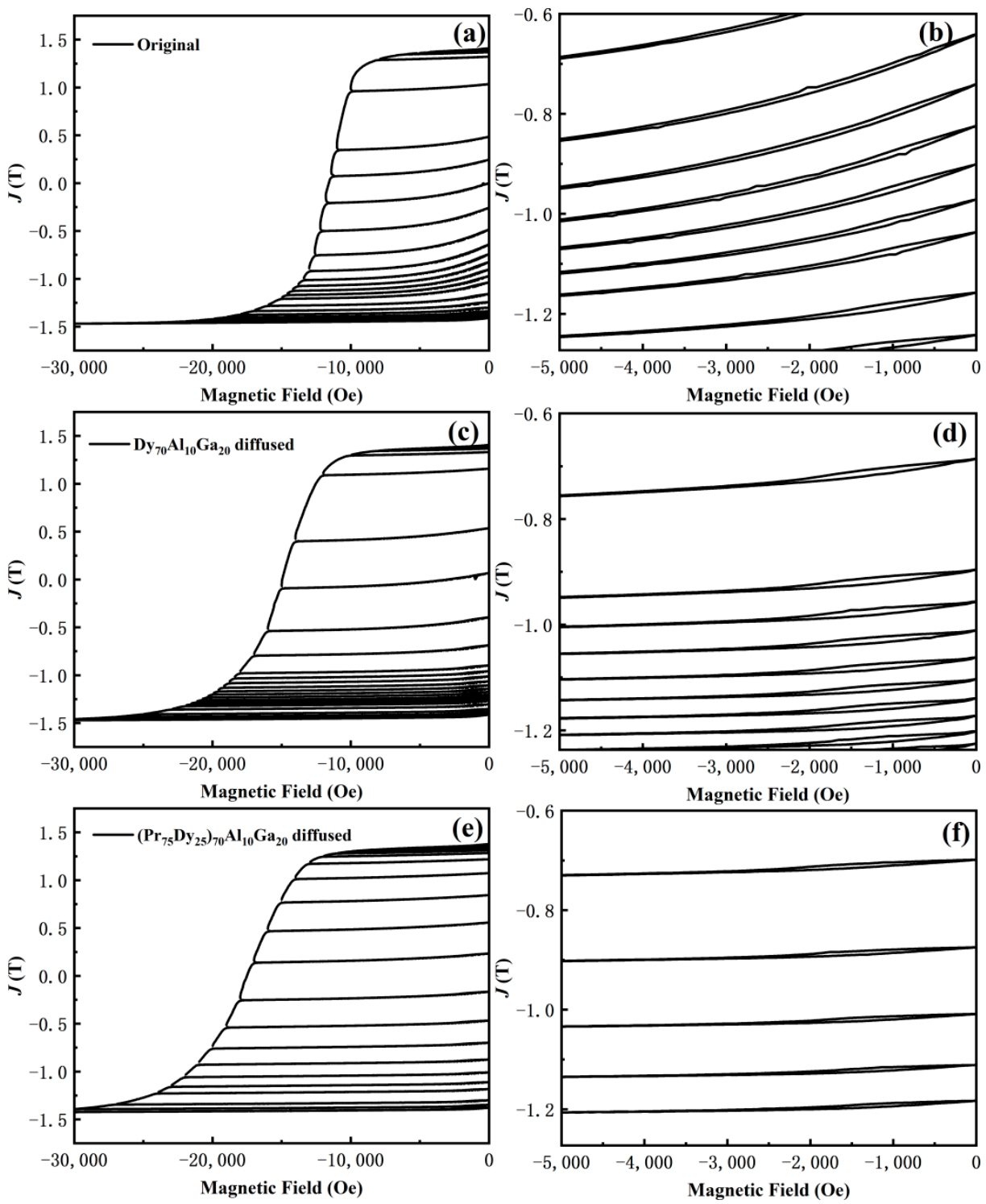

Figure 10. Recoil loops for $(\mathbf{a}, \mathbf{b})$ original magnets, and $(\mathbf{c}, \mathbf{d}) \mathrm{Dy}_{70} \mathrm{Al}_{10} \mathrm{Ga}_{20}$ and $(\mathbf{e}, \mathbf{f})\left(\mathrm{Pr}_{75} \mathrm{Dy}_{25}\right)_{70} \mathrm{Al}_{10} \mathrm{Ga}_{20}$ alloy diffused magnets.

\section{Conclusions}

In this paper, the effects of diffusing $\mathrm{Dy}_{70} \mathrm{Al}_{10} \mathrm{Ga}_{20}$ ternary alloys and $\left(\mathrm{Pr}_{75} \mathrm{Dy}_{25}\right)_{70} \mathrm{Al}_{10} \mathrm{Ga}_{20}$ quaternary alloys on the magnetic properties and microstructure of sintered Nd-Fe-B magnets were investigated.

(1) The coercivity of the $\operatorname{Pr}_{70} \mathrm{Al}_{10} \mathrm{Ga}_{20}, \mathrm{Dy}_{70} \mathrm{Al}_{10} \mathrm{Ga}_{20}$ and $\left(\operatorname{Pr}_{75} \mathrm{Dy}_{25}\right)_{70} \mathrm{Al}_{10} \mathrm{Ga}_{20}$ alloys diffused Nd-Fe-B magnets increased from $13.58 \mathrm{kOe}$ to $15.34 \mathrm{kOe}$ and $20.10 \mathrm{kOe}$ and $18.11 \mathrm{kOe}$, respectively, while the remanence is only slightly decreased.

(2) The thermal stability of the diffused magnets improves by diffusing $\mathrm{Dy}_{70} \mathrm{Al}_{10} \mathrm{Ga}_{20}$ and $\left(\operatorname{Pr}_{75} \mathrm{Dy}_{25}\right)_{70} \mathrm{Al}_{10} \mathrm{Ga}_{20}$ alloys. The $\beta$ increased from $-0.5341 \% / \mathrm{K}$ for the original mag- 
nets to $-0.4609 \% / \mathrm{K}$ and $-0.4939 \% / \mathrm{K}$ for the $\mathrm{Dy}_{70} \mathrm{Al}_{10} \mathrm{Ga}_{20}$ and $\left(\operatorname{Pr}_{75} \mathrm{Dy}_{25}\right)_{70} \mathrm{Al}_{10} \mathrm{Ga}_{20}$ diffused magnets, respectively.

(3) The optimized GB microstructure and ( $\mathrm{Dy}, \mathrm{Pr} / \mathrm{Nd})_{2} \mathrm{Fe}_{14} \mathrm{~B}$ core-shell structure hardening around the main grains isolate the 2:14:1 phases, which are the main reasons for the great improvement of coercivity in the diffused magnets.

(4) The decreased surface Dy enrichment and the optimized grain boundary microstructure lead to the smaller opening of the recoil loops by diffusing the $\left(\operatorname{Pr}_{75} \mathrm{Dy}_{25}\right)_{70} \mathrm{Al}_{10} \mathrm{Ga}_{20}$ alloy. This indicates that the diffused magnet has a stronger capability for demagnetization.

Supplementary Materials: The following are available online at https://www.mdpi.com/article/10 $.3390 / \mathrm{ma14102583/s1}$, Figure S1: Demagnetization curve of the $\left(\operatorname{Pr}_{100-\mathrm{x}} \mathrm{Dy}_{\mathrm{x}}\right)_{70} \mathrm{Al}_{10} \mathrm{Ga}_{20}(\mathrm{x}=0,25,50$, $75,100)$ diffused magnets.

Author Contributions: Formal analysis, P.Q.; funding acquisition, J.L.; investigation, P.Q.; methodology, F.L., L.H., Q.H., and X.Y.; project administration, J.L.; resources, J.L.; supervision, J.L. and M.Y.; writing-original draft, P.Q.; writing—review and editing, P.Q., J.L., and S.U.R. All authors have read and agreed to the published version of the manuscript.

Funding: This work was supported by the National Natural Science Foundation of China (51561009), the Natural Science Foundation of Jiangxi Province (20192BAB206004 and 20202BAB214003), the Key Research and Development Program of Jiangxi Province (20202BBE53014), the Open Foundation of Guo Rui Scientific Innovation Rare Earth Functional Materials Co., Ltd. (KFJJ-2019-0004), the Doctoral Start-up Foundation of Jiangxi University of Science and Technology (205200100110), and the Foundation of Jiangxi Educational Department (GJJ200832 and GJJ190478).

Institutional Review Board Statement: Not applicable.

Informed Consent Statement: Not applicable.

Data Availability Statement: Data sharing is not applicable to this article.

Conflicts of Interest: The authors declare no conflict of interest.

\section{References}

1. Bhuiyan, N.A.; McDonald, A. Optimization of offshore direct drive wind turbine generators with consideration of permanent magnet grade and temperature. IEEE Trans. Energy Convers. 2019, 34, 1105-1114. [CrossRef]

2. Chen, F.G. Recent progress of grain boundary diffusion process of Nd-Fe-B magnets. J. Magn. Magn. Mater. 2020, 514, 167227. [CrossRef]

3. Bai, G.; Gao, R.W.; Sun, Y.; Han, G.B.; Wang, B. Study of high-coercivity sintered NdFeB magnets. J. Magn. Magn. Mater. 2007, 308, 20-23. [CrossRef]

4. Hono, K.; Sepehri-Amin, H. Strategy for high-coercivity Nd-Fe-B magnets. Scr. Mater. 2012, 67, 530-535. [CrossRef]

5. Zhong, S.W.; Yang, M.N.; Rehman, S.U.; Lu, Y.J.; Li, J.J.; Yang, B. Microstructure, magnetic properties and diffusion mechanism of DyMg co-deposited sintered Nd-Fe-B magnets. J. Alloys Compd. 2020, 819, 153002. [CrossRef]

6. Soderznik, M.; Korent, M.; Soderznik, K.Z.; Katter, M.; Üstüner, K.; Kobe, S. High-coercivity Nd-Fe-B magnets obtained with the electrophoretic deposition of submicron $\mathrm{TbF}_{3}$ followed by the grain-boundary diffusion process. Acta Mater. 2016, 115, 278-284. [CrossRef]

7. Loewe, K.; Benke, D.; Kubei, C.; Lienig, T.; Skokov, K.P.; Gutfleisch, O. Grain boundary diffusion of different rare earth elements in Nd-Fe-B sintered magnets by experiment and FEM simulation. Acta Mater. 2017, 124, 421-429. [CrossRef]

8. Liu, Q.B.; Tang, X.; Chen, R.J.; Wang, Z.X.; Ju, J.Y.; Yin, W.Z.; Yan, A.R.; Xu, H. Effect of Tb-Fe diffusion on magnetic properties and thermal stability of hot-deformed magnets. J. Alloys Compd. 2019, 773, 1108-1113. [CrossRef]

9. Park, K.T.; Hiraga, K.; Sagawa, M. Effect of metal-coating and consecutive heat treatment on coercivity of thin Nd-Fe-B sintered magnets, Rare Earths Magnets. Int. Workshop Rare Earth Magn. Appl. 2000.

10. Tang, X.T.; Lu, Z.W.; Sun, A.Z. The effect of sintered Nd-Fe-B with Dy infiltration to the plating crafts. J. Magn. Magn. Mater. 2019, 475, 10-13. [CrossRef]

11. Itakura, M.; Namura, M.; Nishida, M.; Nakamura, H. Elemental Distribution near the Grain Boundary in a Nd-Fe-B Sintered Magnet Subjected to Grain-Boundary Diffusion with $\mathrm{Dy}_{2} \mathrm{O}_{3}$. Mater. Trans. 2020, 61, 438-443. [CrossRef]

12. Xu, F.; Wang, J.; Dong, X.; Zhang, L.; Wu, J. Grain boundary microstructure in $\mathrm{DyF}_{3}$-diffusion processed Nd-Fe-B sintered magnets. J. Alloy Compd. 2011, 509, 7909-7914. [CrossRef]

13. Bae, K.H.; Lee, S.R.; Kim, H.J.; Lee, M.W.; Jang, T.S. Effect of oxygen content of Nd-Fe-B sintered magnet on grain boundary diffusion process of $\mathrm{DyH}_{2}$ dip-coating. J. Appl. Phys. 2015, 118, 297. [CrossRef] 
14. Lu, K.; Bao, X.; Tang, M.; Sun, L.; Li, J.; Gao, X. Influence of annealing on microstructural and magnetic properties of Nd-Fe-B magnets by grain boundary diffusion with Pr-Cu and Dy-Cu alloys. J. Magn. Magn. Mater. 2017, 441, 517-522. [CrossRef]

15. Cao, X.J.; Chen, L.; Guo, S.; Chen, R.J.; Yan, G.L.; Yan, A.R. Impact of $\mathrm{TbF}_{3}$ diffusion on coercivity and microstructure in sintered Nd-Fe-B magnets by electrophoretic deposition. Scr. Mater. 2016, 116, 40-43. [CrossRef]

16. Di, J.H.; Ding, G.F.; Tang, X.; Yang, X.; Guo, S.; Chen, R.J.; Yan, A.R. Highly efficient Tb-utilization in sintered Nd-Fe-B magnets by $\mathrm{Al}$ aided $\mathrm{TbH}_{2}$ grain boundary diffusion. Scr. Mater. 2018, 155, 50-53. [CrossRef]

17. Lu, K.C.; Bao, X.Q.; Zhou, Y.S.; Lv, X.K.; Ding, Y.; Zhang, M.; Wang, C.G.; Gao, X.X. Effect of Al/Cu on the magnetic properties and microstructure of Nd-Fe-B sintered magnet by diffusing Pr-Tb-(Cu, Al) alloys. J. Magn. Magn. Mater. 2020, 500, 166384. [CrossRef]

18. Sasaki, T.T.; Takad, Y.; Okazaki, H.; Ohkubo, T.; Nakamura, T.; Sato, T.; Kato, A.; Kaneko, Y.; Hono, K. Role of Ga on the high coercivity of Nd-rich Ga-doped Nd-Fe-B sintered magnet. J. Alloy Compd. 2019, 790, 750-759. [CrossRef]

19. Lu, K.C.; Bao, X.Q.; Tang, M.H.; Chen, G.X.; Mu, X.; Li, J.H.; Gao, X.X. Boundary optimization and coercivity enhancement of high $(B H)_{\max } \mathrm{Nd}-\mathrm{Fe}-\mathrm{B}$ magnet by diffusing Pr-Tb-Cu-Al alloys. Scr. Mater. 2017, 138, 83-87. [CrossRef]

20. Yan, X.T.; Hou, Y.H.; Shi, Z.Q.; Nie, H.X.; Zhou, Y.X.; Huang, Y.L.; Lou, J.M.; Chen, W.; Pang, Z.S.; Mao, H.Y.; et al. Enhanced magnetic properties and improving thermal stability for sintered Nd-Fe-B magnets prepared by two-step grain boundary diffusion processes. J. Magn. Magn. Mater. 2019, 491, 165541. [CrossRef]

21. Hu, X.J.; Jiang, Q.Z.; Zhong, M.L.; Sajjad, U.R.; Zhong, Z.C.; Li, M.F.; Liu, R.H. Magnetic properties, thermal stabilities and microstructures of melt-spun Misch-Metal-Fe-B alloys. Phys. B Condens. Matter 2019, 567, 118-121. [CrossRef]

22. Li, J.J.; Guo, C.J.; Zhou, T.J.; Qi, Z.Q.; Yu, X.; Yang, B.; Zhu, M.G. Effects of diffusing DyZn film on magnetic properties and thermal stability of sintered NdFeB magnets. J. Magn. Magn. Mater. 2018, 454, 215-220. [CrossRef]

23. Wang, Z.X.; Zhang, J.J.; Wang, J.Z.; Ju, J.Y.; Chen, R.J.; Tang, X.; Yin, W.Z.; Lee, D.; Yan, A.R. Coercivity improvement of hot-deformed Nd-Fe-B magnets by stress-induced Pr-Cu eutectic diffusion. Acta Mater. 2018, 156, 136-145. [CrossRef]

24. Sepehri-Amin, H.; Ohkubo, T.; Hono, K. The mechanism of coercivity enhancement by the grain boundary diffusion process of Nd-Fe-B sintered magnets. Acta Mater. 2013, 61, 1982-1990. [CrossRef]

25. Seelam, U.M.R.; Ohkubo, T.; Abe, T.; Hirosawa, S.; Hono, K. Faceted shell structure in grain boundary diffusion-processed sintered Nd-Fe-B magnets. J. Alloy Compd. 2014, 617, 884-892. [CrossRef]

26. Zhang, Y.; Ma, T.; Liu, X.; Liu, P.; Jin, J.; Zou, J.; Yan, M. Coercivity enhancement of Nd-Fe-B sintered magnets with intergranular adding (Pr, Dy, Cu)-H $\mathrm{H}_{x}$ powders. J. Magn. Magn. Mater. 2016, 399, 159-163. [CrossRef]

27. Ikram, A.; Mehmood, M.F.; Samardžija, Z.; Sheridan, R.; Awais, M.; Walton, A.; Šturm, S.; Kobe, S.; Rožman, K.Z. Coercivity Increase of the Recycled HDDR Nd-Fe-B Powders Doped with DyF3 and Processed via Spark Plasma Sintering \& the Effect of Thermal Treatments. Materials 2019, 12, 1498.

28. Cho, Y.; Sasaki, T.; Harada, K.; Sato, A.; Tamaoka, T.; Shindo, D.; Ohkubo, T.; Hono, K.; Murakami, Y. Magnetic flux density measurements from grain boundary phase in 0.1 at $\%$ Ga-doped Nd-Fe-B sintered magnet. Scr. Mater. 2020, 178, 533-538. [CrossRef]

29. Lu, Y.J.; Zhong, S.W.; Yang, M.N.; Wang, C.M.; Yang, L.Y.M.; Li, L.G.; Yang, B. Nd-Fe-B Magnets: The Gradient Change of Microstructures and the Diffusion Principle after Grain Boundary Diffusion Process. Materials 2019, 12, 3881. [CrossRef] 